\title{
SELF-POWERING SYSTEM FOR UNDER WATER SENSOR NODE
}

\author{
Mrs Sahana Salagare, \\ Research Scholar, K S Institute of Technology, Bengaluru, India
}

Dr. P.N.Sudha,

Prof \& HOD. Dept. of ECE, K S Institute of Technology, Bengaluru, India

Harshini B S, Meenakshi A, Arpitha C V, Chandrakala K S, Department of ECE, K S Institute of Technology, Bengaluru, India

\begin{abstract}
There are many technologies for energy production, ocean wave energy is one among them and is significant as compared to other. Renewable sources such as biomass, solar power are used from ages in our country for the energy production. Anyhow, we are still much behind in scientific use of such technologies. In coastal areas, Ocean wave energy is environmental friendly and is a sustainable solution for secure energy system. Tidal energy contributes an essential part for energy production and becoming much popular for its properties. Tidal energy production can reduce the energy crisis and can improve the economic and environmental status. In this paper we are generating electricity by using wave power of the water which can be best substantiate for energy crisis.
\end{abstract}

\section{INTRODUCTION}

Renewable energy sources are indigenous and non -polluting, they can cope with security of supply chain and environmental issues, hence renewable energy technologies are becoming increasingly favourable to tackle the climatic changes. We use renewable energy in our day to day lives such as usage of biomass, solar and wind energy for cooking, drying of clothes, drying grains respectively. Ocean waves carry a vast pool of energy has been known for a long time. However, we are still lagging behind in the scientific use of such energy. There are several source of renewable energies for example wind, solar, wave or tidal which display several outputs depending on the weather condition. Hydroelectricity is the most sustainable form of energy. Tidal power or tidal energy is a form of hydropower that converts the energy of tides into electrical power. As tides are more predictable than wind and sunlight, tidal energy can easily be generated from the changing sea levels. Tidal energy provides an enormous and a steady source of energy. . The total energy flux of the tides is about $3 \mathrm{TW}$, however only a small fraction of this potential would be harnessed on the foreseeable future. Since, $70 \%$ of the earth has been covered by oceans it has been considered as a vast renewable source of energy. Tidal power is knocking the future for electricity production It can provide remarkable development in the energy sector in future. Underwater sensor nodes can be used for various applications such as oceanographic data collection, pollution monitoring and several other but the main constraint is the battery life which is very difficult to recharge and replace. So designing a model which generates electricity by using a wave power and which can supply energy continuously to the battery is the main objective.

\section{LITERATURE SURVEY}

In papers [1], [2], [3], [4], [5], [6], [7] , the features, architecture and characteristics of wireless sensor node and applications of the wireless sensor node, also specifies the importance of Underwater Communication has been explained and various challenges faced by wireless sensor node and different energy harvesting techniques. In paper [8], solar energy is used as main source of energy for electricity but it cannot be harnessed all the time and can implemented on the seashore. In paper [9], the author explains about the power demand in Bangladesh and the importance of tidal power and the comparison of tidal power with other source of renewable energy. In paper [10], the electricity is generated by using amplitude of the ocean wave and it does not need fuel to maintain and it's a predictable kind of energy as compared to wind and solar, but holding back the tide allows silt to build up on the river bed. In paper [11], the author explains about underwater vehicle which keep in track of marine activities and in order to extract a sample for pollution analysis syringe has been used. In paper [12], the working model of underwater vehicle has been developed which describes the sensor interfacing portion of the project which is interfaced with PIC18 Microcontroller and parameters like temperature, pressure has been measured. In paper [13], author explains about the conventional laws of the sea border limitations and the model also explores interpretation of video footages, photo capture as well as location tracking and updating.

\section{METHODOLOGY}

The system makes use of NodeMcu which runs on ESP8266 Wi-Fi Soc to which DHT11 temperature and humidity sensor is connected. 
International Journal of Engineering Applied Sciences and Technology, 2020

Vol. 5, Issue 4, ISSN No. 2455-2143, Pages 442-444

Published Online August 2020 in IJEAST (http://www.ijeast.com)

Fig: Model of Self- Powering System for Underwater Sensor Node

\section{A. ADVANTAGES}

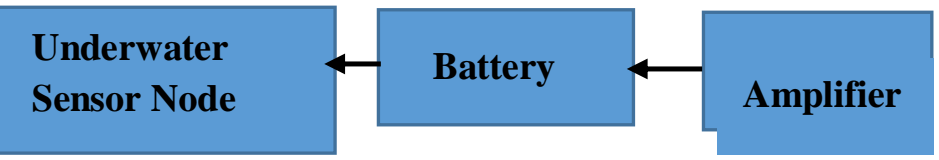

Fig: Block diagram of Self Power system for Underwater Sensor Node

Firstly, a coil is created by winding the copper wire around the test tube. Measurable voltage will be produced by a minimum of 100 coil. The wire is tied to the tube with transparent adhesive tape, an extra length of wire is left free on both ends of the coil to make connections, remove the insulation from the ends of the wire for effective connections which can be done by smoothing the end of the wire with magnetic-grit sandpaper. The wire will be ready and insulation has been stripped if there is zero resistance between the ends of the wire.

Then, to the bottom of test tube a loop of copper wire has to be attached. This will be further attached to a suction cup on the bottom of wave tank and avoids the drifting of tube from the position. In order to keep the tube upright in the tank, flotation collar must be attached. One end of strong plastic string must be tied to magnetic necklace clasp and the other end must be tied to bobber.

Estimate the wave height by drawing a measured lines on the sides of the tank by using a marker. Attach the suction cups to the bottom of tank which will keep the tube in position. Place a cylinder like structure under the tank which will acts as rollers. Gently move the roller back and forth to build waves. Put the coil into the tank and fill the tank about 3-4 inches above the top of the test tube. Then put the float and magnet assembly into the tank with magnet inside the test tube. Move the roller back and forth which will create waves and then waves will go both above and below the fill level which will generate the electricity.

The generated power will be stored in a battery then supplied to a underwater device which is DHT 11 temperature and humidity sensor through NodeMcu and will be able to get the temperature and humidity of an underwater environment.



- Main Source of energy is Wave power which is available abundantly.

- There is no need for extra fuel for maintenance.

- Can send information of underwater environment.

- Battery can be charged continuously, so the battery life of underwater sensor node can be increased.

\section{B. DISADVANTAGES}

- Presently costly.

- Underwater sensor must be insulated, since the chances of corrosion is high.

- The wave movement must be much high to create electricity.

\section{APPLICATIONS}

- Monitoring the environmental conditions of underwater is easy.

- Data can be uploaded to cloud/server which can be useful for future analysis.

- Underwater sensor node is useful for pollution monitoring, oceanographic data collection etc.

\section{RESULT}

A new model has been developed which generates electricity using a wave power and the generated electricity is $0.4 \mathrm{v}$ with then amplified using a power booster to $5 \mathrm{v}$ then it is stored in Lithium ion battery and then supplied to underwater sensor device. Since the energy is generated by using tidal energy which is the renewable source of energy continuous energy is supplied to underwater sensor node. Here we are using

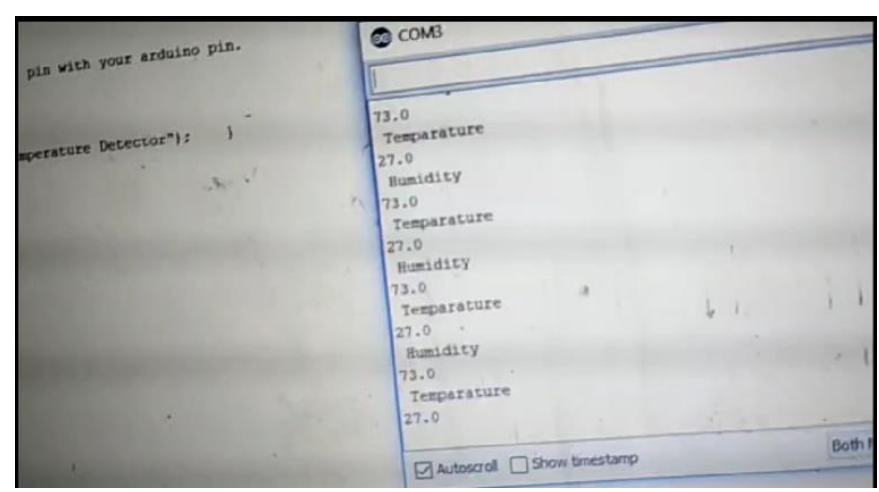

underwater sensor node as DTH11 temperature and humidity sensor which is controlled node MCU.

Fig: Sensor Values

\section{CONCLUSION AND FUTURE WORK}

As the demand for power increases, there a need to develop a technology which can reduce the power crisis. Though there are many technologies to generate electricity using renewable 


\section{International Journal of Engineering Applied Sciences and Technology, 2020 Vol. 5, Issue 4, ISSN No. 2455-2143, Pages 442-444 \\ Published Online August 2020 in IJEAST (http://www.ijeast.com)}

sources such as biomass, solar, wind, wave/tidal, generation of electricity using wave power is fastest growing technology. In this paper, a new model has been developed which generates electricity using wave power which supplies continuous energy to underwater sensor device. Underwater Sensor device helps in oceanographic data collection, pollution monitoring, etc. In future, many of the systems of this kind can be concaded to increase the efficiency of the system.

\section{ACKNOWLEDGEMENT:}

This work was supported by K S Institute of Technology, under the guidance of Mrs. Sahana Salagare, Research Scholar, K S Institute Of Technology, Bengaluru, India.

\section{REFERENCES}

[1]. Ian F. Akyildiz , Dario Pompili, Tommaso Melodia, (2005), "Underwater acoustic sensor networks: research challenges", School of Electrical and Computer Engineering, Georgia Institute of Technology, Atlanta, (Pg 257-279).

[2]. John heidemann, Milica Stojanovic and Michele Zorzi, (2012) "Underwater Sensor Networks: Applications, advances, and Challenges", Philosophical Transactions of the Royal SocietyA.370, 1958, (Pg 158-175) .

[3]. B. Sai Srujana, Neha, Princy Mathews, V.P. Harigovindan, (2015) "Multi-Source Energy Harvesting system for underwater Wireless Sensor Networks", Procedia Computer Science, Volume46, , (Pg 1041-1048).

[4]. Emad Felemban, Faisal Karim Shaikh, Umair Mujtaba Qureshi, Adil A. Sheikh, and Saad Bin Qaisar, (2015) "Underwater sensor network applications: A comprehensive survey" International Journal of Distributed Sensor Networks, (doi - 10.1155).

[5]. SahanaSalagare,Dr.P.N,Sudha, Dr.Karthik P A "Survey on Applications and Challenges of Underwater Wireless Sensor Node", (2016) International Journal of Engineering Trends and Technology (IJETT) - Volume-41 Number-4.

[6].SahanaSalagare, Dr.P.N,Sudha, Dr.Karthik P “ Survey on Energy Harvesting Systems for Underwater Devices" Presented at ICAEM-18 at KSSEM, Bengaluru.
[7]. Harshini B S, Meenakshi A, Arpitha C V, Chandrakala K S, Mrs Sahana Salagare, (2020) "Applications and Research Challenges Of Underwater Communication Devices_ A Review" SSRG International Journal of Electronics and Communication Engineering(SSRG-IJECE)- Volume 7 Issue -2 .

[8]. Pragathi Madhyastha K P, Rashmi Srinivasam, Sanjana, Santhosh K, Sahana Salagare, (2019) “ Solar Powered Unmanned Marine Robot Using Radar System" International Journal of Engineering and Technology(IJERT) ISSN: 22780181, Vol.8 Issue05.

[9]. Md. Alamgir Hossain, Md. Zakir Hossain, Md. Atiqur Rahman, (2014) "Perspective and Challenge of Tidal Power in Bangladesh" International Journal of Energy and Power Engineering Vol:8, No:7.

[10]. A.H.M. Zadidul Karim, MD.Mizanur Rahman, Subrata Karmoker, "Electricity Generation by Using Amplitude of Ocean Wave" Conference September 2015.

[11]. Abhishek A Nandyal, Adithya D M, Karthik K, Manikantan G, Dr. P.N. Sudha, (March- 2020) "A Literature Survey On Unmanned Underwater Vehicle For Monitoring Aquatic Ecosystem", International Journal of Engineering Applied Sciences and Technology, 2020 Vol. 5, Issue 2, ISSN No. 2455-2143, (Pg 599-601).

[12]. Abhishek A Nandyal, Adithya D M, Karthik K, Manikantan G, Dr. P.N. Sudha, (July- 2020) "A Literature Survey On Unmanned Underwater Vehicle For Monitoring Aquatic Ecosystem", International Journal of Engineering Applied Sciences and Technology, 2020 Vol. 5, Issue 2, ISSN No. 2455-2143, (Pg 599-601).

[13]. Yashaswini S, Arpitha S R, Banda Tejavardhan, Prasad Poojary, Mrs. Sahana salagare (2018) "A Smart Catamaran Cruise" International Journal of Engineering Research and Technology (IJERT), Vol. 6, Issue 15, ISSN No. 2278-0181. 